\title{
'A Hero Mumsy': Parenting, Power and Production Changes in The Sarah Jane Adventures
}

Victoria Byard

The Sarah Jane Adventures (BBC 2007-11) was originally intended by the BBC's children's channel, CBBC, to be a show revolving around 'a teenage Doctor - described as "Young Doctor Who" - aimed at the children's market'. ${ }^{1}$ When approached by CBBC, Russell T Davies, showrunner, chief writer and executive producer of the regenerated Doctor Who (BBC 2005-), was unenthusiastic about the idea and instead suggested a programme about previous Companion to the third and fourth Doctors, Sarah Jane Smith, and her robot dog, K9. The award-winning programme about the adventures of Sarah Jane, her adoptive son, Luke, and their friends defending the Earth against alien threats subsequently ran for five series and was only cut short by the death of the star, Lis Sladen, in 2011.

While the history of Doctor Who has been documented exhaustively, The Sarah Jane Adventures has attracted less attention, arguably as a consequence of the scheduling, tone and production economies which situate it as children's television, itself often overlooked within the academy. This discussion will analyse how The Sarah Jane Adventures evolved out of Doctor Who and a canon of British children's television and how it differentiated itself from its parent text. The Sarah Jane Adventures defied many of the expectations of spin-offs as commercial and restricted opportunities by adapting the BBC's flagship drama Doctor Who for the public service broadcasting arena of children's television while simultaneously sustaining a reciprocal relationship with the parent text. This adaptation was facilitated by a previous re-visioning within Who itself that combined genre characteristics from science fiction and soap opera ${ }^{2}$ while adding what Ien Ang, in her work on viewer engagement with US soaps, called 'emotional realism'. ${ }^{3}$ Matt Hills's review of The Sarah Jane Adventures' truncated fifth series suggests that 
the text's self-referential nature, as well as its 'perpetuated hermeneutic' and 'hyperdiegesis', might constitute 'its own continuity: a Sarahverse intertwined with the Doctor's own Whoniverse' ${ }^{4}$ In the same review, Hills suggests that 'perhaps $S J A$ 's focus on stories of maternal care make it the true "mothership" of the franchise".

This discussion suggests that these 'stories of maternal care' are, indeed, the key adaptive process of The Sarah Jane Adventures. They are not only used to rearticulate the Sarah Jane of Doctor Who into the Sarah Jane of her own adventures but to establish familial and social relationships and responsibilities as part of a discourse of British citizenship and childhood in line with the long-standing ethos of BBC Children's Programmes. ${ }^{5}$ The parent-child relationship is also used to mediate diegetic reality and understandings of humanity, thereby providing a flexible but stable ideology to the text. 'Emotional realism' operates predominantly within The Sarah Jane Adventures through the parentchild relationship, often interrogated, but always, as a normalised eth-ics of care, community and familiarity, acting as an anchor for textual reality and alterity as well as genre. Relationships between adults and children, and particularly parents and children, are both valorised and questioned in The Sarah Jane Adventures and illustrate the adaptive shifts within the text and production culture which reorient Who into Sarah Jane; flagship drama into children's television.

The Sarah Jane Adventures ostensibly originates from its parent programme, Doctor Who (BBC 1963-89), for which the character of investigative reporter Sarah Jane Smith was developed. Her two seasons in 'classic' Doctor Who created a lasting affection for Sarah Jane as one of the most popular Companions; consequently, when a spin-off was suggested for children's television it drew on this textual and cultural history. Yet it was a problematic history to use within contemporary children's television. It was arguably unfamiliar to CBBC's target audience of six to 12-year-olds; unless child viewers were committed Who fans, they would be unaware of her previous appearances in the canon. In addition, the character of Sarah Jane Smith from classic Doctor Who - bolshy, independent, handy with a rifle - would not necessarily fit comfort- ably into the conventions and tradition of children's television. Sarah Jane had, however, been resurrected in 2006 for the new Who episode, 'School Reunion', which not only reintroduced a classic character for the audience but also suggested one of the tensions germane to Doctor Who and, by corollary, The Sarah Jane Adventures: the recapitulation of the Who franchise by fan-producers, and the concomitant anxieties and pleasures of nostalgia, authenticity and canonicity. ${ }^{6}$ 
Doctor Who's interregnum between 1989 and 2005 opened up both demand and diegesis as fans started to produce and publish their own material; this material, as well as earlier officially sanctioned prod-ucts, became the heart of a particular continuity issue when Who was regenerated. Some of the fans producing material during this period subsequently became official producers within the new Who franchise and incorporated 'non-canonical' material into Who diegesis, further destabilising the boundaries between producers and consumers, canon and 'fanon'. 'This is equally true in The Sarah Jane Adventures, as evidenced by the involvement of fan-producers, such as Gareth Roberts and Joseph Lidster, who got their start in the interregnal Who period, as well as the incorporation of fan-produced material into the 'Sarahverse' 16 years later: a 1992 Doctor Who Magazine special edition provided the backstory for the death of Sarah Jane's parents, elaborated upon in 'The Temptation of Sarah Jane Smith' in $2008 .^{8}$

'School Reunion' engages with these anxieties and pleasures by 'discarding and cherry-picking continuity', suggests Tony Keen, particularly since the episode 'implies heavily that Sarah has had no contact with the Doctor since he abandoned her in Aberdeen' at the end of 'The Hand of Fear'. ${ }^{9}$ This elides the events of both 'The Five Doctors' and $K 9$ and Company (BBC 1981), an earlier attempt at a Who spin-off, featuring Sarah Jane and the robot dog. Keen argues that this complicates continuity further because Sarah Jane and K9 never encountered each other in the Who diegesis; without $K 9$ and Company, there is no reasonable explanation for Sarah having K9 who features heavily in the Adventures. The regeneration of Sarah Jane for new Who could, however, capitalise on nostalgia for classic Who as well as 'retcon' the complex character history, thereby reconfiguring her for a new audience in children's television. Clearly, then, The Sarah Jane Adventures does not originate solely from Doctor Who as a closed and stable text but is rather a palimpsest selectively built on the heterogeneous media of Doctor Who - official canon, fan-produced media and previous spin-off - and over 60 years of BBC children's television.

Sarah Jane's rearticulation is therefore given a jumpstart in 'School Reunion' which suggests that she has become bitter and isolated since the Doctor left her, convinced that nothing could live up to her previ- ous existence as a Companion. By the episode's end, however, she concludes 'Time I stopped waiting for you and found a life of my own.' Not only does this suggest a complex meta-textual history for Sarah Jane, it also reorients her characterisation from classic Who towards a more soap drama approach, incorporating 'the psychologising of character 
and [an] emphasis on affect', which Bould suggests defines new Who as part of 'a more contemporary articulation of present social experience [which must] be understood in terms of an industry emphasis on a property's "emotional capital", ${ }^{10}$

The social experience and emotional capital of The Sarah Jane Adventures are invested primarily within the relationship between parent and child as a nexus of authority, care and reality checking, and this relationship is extrapolated globally by explicitly locating threats to children as threats to humanity. The first hour-long episode of The Sarah Jane Adventures, 'Invasion of the Bane', completes this affective, generic and intratextual remediation of Sarah Jane Smith by making her the adoptive mother to a genetically engineered Archetype, Luke, who under Sarah Jane's tutelage and care defies his programming to help her save the world.

While the parent-child relationship acts as the principal mechanism by which The Sarah Jane Adventures is adapted for children's television, it is also the dynamic which formally differentiates The Sarah Jane Adventures from Doctor Who, and the Sarah Jane of classic Who from the regenerated Sarah Jane. She is re-inscribed locally as a mother to Luke and later Sky, as well as globally with the same ethics of care and maternal authority imbricated onto her role as hero and defender of Earth. The opening episodes of the first series in January 2007 explicitly mark out this difference through two parallel parent-child relation- ships. Where 'Invasion of the Bane' transformed Sarah Jane from an isolated and lonely 'mad woman' into an adoptive mother, 'Revenge of the Slitheen' substantiates her role as protective parent and incorporates maternal values into her previous role as Companion. 'Revenge' carves out this new maternal space for Sarah Jane by directly referencing her previous ethical stance in classic Who.

Thirty years before, in the Doctor Who story 'Genesis of the Daleks' (1975), Sarah Jane had advocated that the Doctor, deep in the throes of an ethical dilemma, should destroy the Daleks before they could achieve sentience and potentially destroy the universe. The Doctor responded, 'If someone who knew the future pointed a child to you and told you that that child would grow up totally evil, to be a ruthless dictator who would destroy countless millions of lives, could you then kill that child?' This thought experiment becomes textually concrete in 'Revenge' when the defeated Slitheen, previously intent on destroying Earth for profit, plead with Sarah Jane to release their child from the fatal trap in which they are caught. Sarah Jane tries to release the Slitheen child when it is revealed that he is only 12 and his 
father pleads, 'He's my son. Please let him live.' The parallels with her own newly adopted child and that hypothetical child in 'Genesis' are obvious: Sarah Jane moves to free the Slitheen child but her hesitation ostensibly causes the death of both Slitheen, subsequently providing the impetus for the concluding episode of the series, 'The Lost Boy' (2007). Sarah Jane's regenerated identity is created by her new maternal ethics, a philosophical and affective position reinforced by her denial of any involvement in the Slitheen's death. Luke's friend, Clyde, is invested with Sarah Jane's previous ethical position, countering Sarah Jane's regretful, 'He was a child: twelve years old' with 'It was them or us.' This reconfigured ethical stance is reinforced later, when in the episode 'The Last Sontaran' (2008) Sarah Jane declares that 'one life is as sacred as an entire planet', reversing her previous utilitarianism in classic Who. Sarah Jane's ideology becomes commensurate with the ethics of care and empathy focalised through her maternal role, so that she performs these reformulated ethics of compassion, liberalism and learning, and by corollary the long-standing ethics and ethos of the BBC Children's Programmes department, across domestic, public and universal spaces. She is repeatedly identified as the template for the ethical human, and subsequent hero-figures, particularly girls, are articulated as iterations of Sarah Jane herself whenever they perform her maternal ethics of care and communication. ${ }^{11}$

Sarah Jane's maternal role is therefore deliberately imbricated with her commitment to defending the Earth but it is only because of her relationship with Luke and consequently with the other child protagonists that she is able to continue doing so. The future echoes of a Sarah Jane without the maternal role are played out across multiple episodes in which the mad, childless, old women of Rani, Bea, and Sarah Jane herself are marginalised and abused. ${ }^{12}$ Indeed, the first two series open and conclude with episodes that emphasise the formal and narrative importance of the parental relationship which Sarah Jane has formed with Luke, Maria and Clyde. When Sarah Jane is accused of abducting Luke in 'The Lost Boy', specific reference is made to her isolation, loneliness and possible mental instability: Luke's alleged parents explicitly articulate the negative image of Sarah Jane before she became a mother as childless and 'lonely', a 'witch'. Sarah Jane without the maternal role is repeatedly cast as a figure of suspicion, mockery and social exclusion. After Luke is taken away from her, Sarah Jane cuts herself off from other relationships, regressing to her previous reckless and autocratic behaviour. Without Luke, and the web of community relationships that subsequently forms, the series implies that she would not only be 
unable to function as a defender of the Earth but also as part of society. Parenthood is, then, not just redemptive for the adult but for the world: threats to Earth can be defused by a parental ethics of care and parental love, even across species.

Even those Adventures which do not directly concern Sarah Jane's relationships with children often revolve around parent-child relationships which are either ruptured or unhealthy. Garner rightly points out Sarah Jane is constructed as 'the good adult' in opposition to other adult characters: Maria's troubled relationship with her absent mother, Chrissie, may equally suggest the 'bad mother' to Sarah Jane's 'good' mother. ${ }^{13}$ Chrissie invades the family home and destabilises and fractures the parent-child relationship, herself becoming the alien threat. She consistently attempts to check Maria's relationship with Sarah Jane, resenting her replacement and stating that Sarah Jane is not nor- mal, accusations which Maria counters by pointing out in 'Eye of the Gorgon' that Chrissie 'walked out' on her own child. Similar dynamics operate within Clyde's relationship with his father who returns home only because he is in the process of abandoning another son. During Clyde's attempt at reconciliation, his father endangers him physically and mentally in 'The Mark of the Berserker' (2009) by compelling Clyde to forget his mother. SF tropes such as defamiliarisation, mind control and possession metaphorically express the lived experiences and divided loyalties of children with absent parents. In The Sarah Jane Adventures the parental role must be performed consistently and care- fully for it to be 'proper' and powerful; absent parents reappear but can only mimic parenting, most often for personal gain. Sarah Jane there- fore performs the 'good mother' role for Maria in 'The Last Sontaran', calling her 'the daughter I always wanted'.

This performance of 'good mother' is universal; Sarah Jane performs and promulgates this ethics of care towards the child protagonists, humanity and visiting aliens. Articulating care and concern for chil- dren is redemptive even for antagonists: Kudlak in 'Warriors of Kudlak' (2007) repents his actions and promises to return the children he has press-ganged. At the very least, care for children opens up the text to emotional ambiguity, as with Luke's biological mother, Mrs Wormwood. Only those who threaten and co-opt children are beyond redemption. ${ }^{14}$ The conflation of threats to the child-figure and threats to humanity as a whole, and the obverse redemptive power of parental love, is reiter- ated in 'Day of the Clown', when Sarah Jane confronts an alien who feeds on ' $[t]$ he fear of a mother for her young: the strongest fear of all'. Across all five series of the Adventures, parental care is a synecdoche for 
ethics and a wider discourse of citizenship and collectivism: alterity can be reconciled with humanity, but posing a threat to a child, which symbolises that humanity, is a marker of incomprehensible alienness.

Conversely, parenting is at times presented as a threat to the wellbeing and ethics of the child. The Slitheen declare that they are planning to destroy Earth 'for our children' but also for revenge and profit; subsequently, the Child of the Slitheen returns in 'The Lost Boy' to destroy the world for the same reasons. Adventures suggests parenting can generate and perpetuate selfish, destructive behaviour unless it incorporates values of citizenship, learning and multiculturalism which are then extrapolated outwards to a broader conception of community and an integration of the Other. When Mrs Wormwood returns in 'Enemy of the Bane', she attempts to charm Luke back to her side, declaring that 'Sarah Jane Smith was the wet-nurse! I am your mother,' and promising him that he will be a prince in the new 'Age of Wormwood'. Her framing of their relationship, as well as the emotive extra-diegetic music, suggest that perhaps her feelings are genuine. Ultimately, Luke rejects her for Sarah Jane who counters Wormwood's claims of motherhood with 'Luke is $m y$ son! Because I have cared for him and looked after him, because I love him. And you don't understand love. People who understand love don't want to crush planets or take over the universe,' once again making a 'good' parental relationship contiguous with presence as well as ethical humanity.

The 'good' parent-child relationship is also strengthened by reciprocal caretaking. Following Clyde's rejection of his father, he wipes his mother's recollection of the day's events in 'The Mark of the Berserker' to keep her 'safe' and 'happy'. In 'The Wedding of Sarah Jane Smith', Rani and Clyde investigate Sarah Jane's relationship with Peter Dalton when they suspect that he is an alien impostor, and in 'Temptation', Luke mediates Sarah Jane's own responsibility and reality when she attempts to save her own parents at the cost of the rest of the world. In turn, her parents sacrifice themselves to save their daughter and Earth. Child protagonists engage in reciprocal caretaking and secret-keeping to keep their parents safe, happy and, above all, 'good' parents. The values of caretaking and citizenship are reflexive: transmitted between Sarah Jane and her parents (and the Doctor) and in turn between Sarah Jane and various child protagonists. These twenty-first-century ethics are disseminated by Sarah Jane, and the BBC, through space and time; in 'Temptation' Rani crashes a 1950s village fête, shouting, 'Yes, hello! Ethnic person in the 1950s!' identifying but also collapsing the two time periods into a space where an 'ethnic person' can be a defender of the 
citizenship and democratic principles which BBC children's broadcasting has promulgated since its inception. These principles extend to the child audience via direct address and incorporation of the viewers in The Sarah Jane Alien Files and The Sarah Jane Adventures roadshows in which viewers could go on their own Adventures. ${ }^{15}$

The presence of Sarah Jane as a mother situates the Adventures within contemporary British children's television through its focus on ethics of care, chosen families, and social integration and responsibility, but it also incorporates quotidian issues more familiar from children's programmes such as The Story of Tracy Beaker (BBC 2002-6) or Grange Hill (BBC 1978-2008). 'The Lost Boy' delays the reveal of the fantastic until after Luke has been threatened and imprisoned by his alleged father, deliberately suggesting that there may not be any fantasy behind the father's behaviour: that this might be child abuse by a parent. When Luke's abusive parents turn out to be vengeful Slitheen, the fantastic gives an escape textually and narratively from quotidian social issues but the moment of Todorovan hesitation is disturbing. ${ }^{16}$ This tension between reality and the fantastic is also referenced meta-textually, again often through parental figures. In 'Revenge of the Slitheen' Sarah Jane, in questioning Maria's dad, conveniently one of the contractors who worked for the aliens, says brightly, 'Ooh, something mysterious inside a school. That would be ridiculous, wouldn't it?', alluding to her previ- ous appearance in 'School Reunion', and possibly also Davies's previous children's television fantasy Dark Season (BBC 1991). Even aliens interrogate the plausibility of the text: Ship in 'Mad Woman' suggests that a robot dog in orbit around a black hole is 'rather improbable'. The programme is repeatedly textually and generically anchored by a diegetic identification of its own (im)plausibility that simultaneously privileges the child viewer as someone who will see, believe and most importantly engage narratively and ethically.

The intertextual references, paratexts and metatexts, such as The Sarah Jane Alien Files and Adventures roadshows to interact with its child audience, locate the 'Sarahverse' as a managed participatory experience which reifies the values of BBC children's television. A participatory ethos has been part of BBC children's television since its inception and is continued and particularised in Adventures' audience interaction. ${ }^{17}$ Paratexts such as its credit sequence, which re-configures the time- vortex of Who's credits into a cryptographic matrix, and further textual references to problem-solving, hermeneutics and education reify children's learning as a positive and participatory activity. ${ }^{18}$ Adventures' core values of democracy, participation and, most importantly, citizenship 
and learning, locate the programme, as suggested earlier, within the particularised media discourse of BBC children's television. Oswell suggests that '[ $\mathrm{t}$ ]here was an importance attached to [early] children's television's textuality in terms of its ability to constitute a series of diegetic worlds distinct from those of the domestic sphere and yet aligned with it'; The Sarah Jane Adventures carries on this ability by constructing a series of diegetic worlds into which the protagonists, and viewers, can carry the values of twenty-first-century BBC children's television, always returning to protect the domestic spheres of the home and the home planet. ${ }^{19}$

The Sarah Jane Adventures therefore perpetuates learning and entertainment within a specific BBC children's television tradition but it is very much contemporary children's television. Post-2003, BBC children's television is increasingly as inflected by commercial anxieties as it is by public service values. The BBC 'Creative Future' initiative of 2006 incorporated many of the features of the theorised TVIII era, and TVIII's practices and profits are articulated through the Adventures' employment of branding, digital technology and transmedia production. ${ }^{20}$ The third series was promoted through its adoption of High Definition filming; however, series filming, and the programme's existence, was threatened by a decreased budget which Davies addressed in a 2009 BAFTA talk, stating that British children's television as a whole was under threat from lack of investment and deregulation. The 'Creative Future' plan also linked public service broadcasting values with the technological and institutional developments of TVIII. This ' 360 degree cross-platform content' is a key feature of the development of The Sarah Jane Adventures, which operates across digital and traditional platforms but once again uses departures from the parent text and platform to complicate the text. ${ }^{21}$ Red Bee Media, formerly BBC Broadcast Ltd, was commissioned to create Adventures trailers for television and cinema which extended

the branding by incorporating interactive and web media that, like Alien Files, destabilised the boundaries between reality and the diegesis of the Adventures. The sense of wonder in the programme is not only immediately available but participatory, creative and cross-platform, though paradoxically controlled through branding. The BBC used further transmedia storytelling in Adventures by only revealing the origin of Sarah Jane's sonic lipstick and watch on the series' website, and incorporating transmedia game-playing and storytelling into the narrative by inviting website users to become part of an Academy, encouraged and instructed by Luke, Clyde and Rani.

The development of The Sarah Jane Adventures is therefore textually and institutionally linked to TVIII broadcasting models incorporating 
new media, time-shifting and branding. However, the intertextual references to a shared past in children's television and Who, as well as the promotion of values of citizenship, learning and the ethics of care through family and community interaction, suggest BBC Children's Television as a brand in and of itself. Throughout the Adventures, BBC children's television acts as both a shared history and as an ethical and liberal participatory practice. The nostalgia of The Sarah Jane Adventures is not only for Sarah Jane herself and the associated era of classic Who but for BBC children's television as a national tradition.

The Sarah Jane Adventures is produced within a children's television economy that is increasingly besieged by economic pressures and benefits from being a commercially successful text which could negotiate the anxieties of education versus entertainment but despite its contem- porary production and transmission, BBC children's television is still a particularised and contingent discourse. Historically, it has been anxiously monitored for values of education and entertainment, moral and public service values. However, in 'Invasion of the Bane' the presenters' promotion of the alien drink Bubble Shock on Blue Peter, a landmark in BBC public service children's television, signifies estrangement and threat, suggesting the perils of an imbalance in commercial and public service pressures. Adventures is located within contemporary children's television by its TVIII production values, its digital presence, and by such generic anchors as the appearance of contemporary Blue Peter transmissions within the diegesis, but it simultaneously invokes the history of children's television in Britain, as does Russell T Davies's statement that Adventures was inspired and inflected by British children's television's 'fine history of fantasy thrillers'. ${ }^{22}$ This holding in tension of contemporary children's television culture - epitomised by its multicultural approach, quotidian social issues and its transmedia structure and the tradition of British children's television through public service values, intertextuality, paratexts and scheduling therefore suggests that Adventures is perhaps not 'pure' children's television.

Children themselves have historically transgressed the boundaries of adult/child media but one complaint made to the viewer comment programme Points of View (BBC 1961-69, 1979-present) was that The Sarah Jane Adventures was " "hidden away" on CBBC rather than being given a more prominent slot that would be more accessible for adults'. ${ }^{23}$ However, with the advent of time-shifting and digital media, children's television has an existence beyond terrestrial schedules and channel identities. The intratextual interaction of the Adventures with Who as well as the attention paid to it in fan discourses and broadsheet media 
further suggest that it may not be, as Perryman suggests, 'designed to appeal exclusively to young children via Children's BBC (CBBC)'. ${ }^{24}$ It may also be designed to engage with the 'migratory behaviour' of adult Who fans. ${ }^{25}$ The presence of a 'second, hidden text' which is more complex and less accessible to children, a 'shadow text', within the programme itself also suggests an older audience. ${ }^{26}$ Not only does Adventures incorporate narrative from classic, interregnal and new Who as well as intertextual references to historical SF and popular media but

it has also regenerated other previous classic Who Companions and characters. Would CBBC's target audience of six- to 12-year-olds get excited about the Brigadier or Jo Jones, to date unseen in new Who? Would they be aware of the significance of former Play School (BBC 1964-88) presenter Floella Benjamin's performance as Professor Celeste Rivers? Further textual allusions to British children's television as a shared history are made within Adventures, such as the Shopkeeper's similarities in costume, mise-en-scène and characterisation to the Shopkeeper in Mr Benn (BBC 1971-72). ${ }^{27}$ Sarah Jane's alien supercomputer, Mr Smith, 'was heavily inspired by the computer TIM which had featured in the 1970s Thames children's adventure series The Tomorrow People [1973-79] of which Gareth [Roberts, the writer] was a devotee'. ${ }^{28}$

The Sarah Jane Adventures, then, transcends mere spin-off status by

incorporating and engaging with the heterogeneous production history of Who 'canon', contemporary institutional and cultural concerns, and almost 70 years of British children's television history, regenerating Who and Sarah Jane for a new audience and new media discourse.

Adventures operates on multiple levels through its 'shadow text' of intertextuality and nostalgia, its formal, aesthetic and cross-platform production properties, and reciprocal appearances of characters across the Who and Adventures diegeses. ${ }^{29}$ Garner suggests that the Doctor's appearances in Adventures are not just audience-raising gambits but an ongoing dynamic of transtextual narrative in which 'the established conventions of a series may be altered through bringing in a "star" character from a parent series', thus altering textual form. ${ }^{30}$ 'The Wedding of Sarah Jane Smith' does, indeed, alter textual form by imbricating the Adventures with its parent text through the Doctor's appearance, but its focus is still emphatically Sarah Jane as a 'good mother' and defender of the Earth. She is encouraged to surrender so that she can 'save them: Luke and the others', her son and humankind who are, to all intents and purposes, one.

Sarah Jane Smith is the most important person in the Sarahverse not because she is heroic but because she is a parent. Her maternal 
relationship with Luke and subsequent relationships mediate ethics and the fantastic within The Sarah Jane Adventures. Her regeneration into a mother is redemptive, allowing her to function effectively within the textual universe of Adventures and British children's television, and her ethics of care and concern for children also inform her role as contemporary hero and differentiate her from her previous incarnations. As the embodiment of the ethos of BBC children's television, she produces, performs and presents civic responsibility, learning and active empathy, as values to be employed day to day, not just by characters but by viewers as well, no matter their age.

\section{Notes}

1. A. Pixley, Doctor Who Magazine Special Edition 23: Sarah Jane Smith (2009), p. 13.

2. R. Garner, "Don't You Forget About Me": Intertextuality and Generic Anchoring in The Sarah Jane Adventures', in R. Garner, M. Beattie and U. McCormack (eds), Impossible Worlds, Impossible Things: Cultural Perspectives on Doctor Who, Torchwood and The Sarah Jane Adventures (Newcastle: Cambridge Scholars, 2010), p. 165.

3. I. Ang, Watching Dallas: Soap Opera and the Melodramatic Imagination, trans. D. Couling (London: Routledge, 1989).

4. M.Hills, Review of Series 5 of The Sarah JaneAdventures, Doctor WhoNews (2011), http://sjaguide.doctorwhonews.net/story.php?story=Sky\& detail=reviews.

5. D. Oswell, Television, Childhood and the Home: A History of the Making of the Child Television Audience in Britain (Oxford: Clarendon, 2002), p. 50.

6. A. McKee, 'How to Tell the Difference Between Production and Consumption: A Case Study in Doctor Who Fandom', in S. Gwenllian-Jones and R. Pearson (eds), Cult Television (Minneapolis and London: University of Minnesota Press, 2004), pp. 167-85; M. Booy, Love and Monsters: The Doctor Who Experience, 1979 to the Present (London and New York: I. B. Tauris, 2012).

7. C. Marlow, 'The Folding Text: Doctor Who, Adaptation and Fan Fiction', in R. Carroll (ed.), Adaptation in Contemporary Culture: Textual Infidelities (London and New York: Continuum, 2009), pp. 46-57.

8. K. W. Parker, 'The Roving Reporter', in G. Russell (ed.), Doctor Who Magazine: Holiday Special (London: Marvel, 1992), pp. 4-7.

9. A. Keen, 'Whatever Happened to Sarah Jane?', in S. Bradshaw, G. Sleight and T. Keen (eds), The Unsilent Library: Essays on the Russell T Davies Era of the New Doctor Who (London: Science Fiction Foundation, 2011), www. sffoundation.org/node/179.

10. M. Bould, 'Doctor Who: Adaptations and Flows', in J. P. Telotte and

G. Duchovnay (eds), Science Fiction Film, Television and Adaptation: Across the Screens (New York and Oxford: Routledge, 2012), p. 156.

11. Heroic, caring girls include Rani in 'Secret of the Stars' (2008), Maria in 'The Mad Woman in the Attic' (2009), Emily in 'Lost in Time' (2010) and Adriana in 'The Man Who Never Was' (2011).

12. See 'Invasion of the Bane', 'Eye of the Gorgon' (2007), 'The Lost Boy' (2007) and 'The Mad Woman in the Attic'. 
13. Garner, 'Don't You Forget About Me', p. 167.

14. Examples include Grantham in 'Warriors of Kudlak'; Miss Myers in 'Sky' (2011); Odd Bob in 'The Day of the Clown' (2008) and the Trickster in 'Whatever Happened to Sarah Jane?' (2007), 'The Temptation of Sarah Jane Smith' (2008) and 'The Wedding of Sarah Jane Smith' (2009).

15. Pixley, Doctor Who Magazine: Sarah Jane Companion, no. 2, p. 51.

16. 'The fantastic is that hesitation experienced by a person who knows only the laws of nature, confronting an apparently supernatural event,' T. Todorov, The Fantastic: A Structural Approach to a Literary Genre (New York: Cornell University Press, 1975), p. 25.

17. Oswell, Television, Childhood and the Home, p. 47.

18. Hills, Review of Series 5 of Adventures.

19. Oswell, Television, Childhood and the Home, p. 49.

20. G. Creeber and M. Hills, 'Editorial - TV III: Into, or Towards, a New Television Age', New Review of Film and Television Studies, 5:1 (2007), 1-4; C. Johnson, 'Tele-branding in TVIII: The Network as Brand and the Programme as Brand', New Review of Film and Television Studies, 5:1 (2007), 5-24; M. C. Rogers, M. Epstein and J. L. Reeves, 'The Sopranos as HBO Brand Equity: The Art of Commerce in the Age of Digital Reproduction', in D. Lavery (ed.), This Thing of Ours: Investigating The Sopranos (New York: Columbia University Press, 2002), pp. 42-57.

21. BBC Creative Futures press release (2006), www.bbc.co.uk/pressoffice/press releases/stories/2006/04_april/25/creative.shtml.

22. BBC press release announcing The Sarah Jane Adventures (2006), www.bbc. co.uk/pressoffice/pressreleases/stories/2006/09_september/14/sarah.shtml.

23. A. Pixley, Doctor Who Magazine Special Edition 28: Sarah Jane Companion, no. 2 (2011), 53.

24. N. Perryman, 'Doctor Who and the Convergence of Media: A Case Study in Transmedia Storytelling', Convergence: The International Journal of Research into New Media Technologies, 14:1 (2008), 35.

25. H. Jenkins, Convergence Culture: Where Old and New Media Collide (New York University Press, 2008), p. 2.

26. P. Nodelman, The Hidden Adult: Defining Children's Literature (Baltimore: Johns Hopkins University Press, 2008), p. 8.

27. Pixley, Doctor Who Magazine: Sarah Jane Companion, no. 2, p. 97.

28. Pixley, Doctor Who Magazine Special Edition 23: Sarah Jane Smith, p. 15.

29. See 'The Stolen Earth' and 'Journey's End' in Doctor Who (2008) and the Doctor Who Christmas Special, 'The End of Time' (2010).

30. Garner, 'Don't You Forget About Me', p. 162. 